\title{
DERMOVILITE EXSUDATIVA VEGETANTE CRÔNICA EM EQUINO - relato de caso
}

\section{Chronic equine proliferative pododermatitis - case report}

\author{
Valeska Andrea Ático Braga ${ }^{1 *}$,, Ramon Cerqueira de Santana ${ }^{2}$, Beatriz Berlinck d'Utra Vaz ${ }^{3}$ \\ *Autor Correspondente: Valeska Andrea Ático Braga. Rua Dom Manuel de Medeiros, s/n, \\ Dois Irmãos, Recife, PE, Brasil. CEP: 52171-900. \\ E-mail: valeskaatico@gmail.com
}

\begin{abstract}
Como citar: BRAGA, V. A. A.; SANTANA, R. C.; VAZ, B. B. U. Dermovilite exsudativa vegetante crônica em equino - relato de caso. Revista de Educação Continuada em Medicina Veterinária e Zootecnia do CRMV-SP, São Paulo, v. 19, n. 1, 2021. DOl: https://doi.org/10.36440/recmvz.v19i1.38197.

Cite as: BRAGA, V. A. A.; SANTANA, R. C.; VAZ, B. B. U. Chronic equine proliferative pododermatitis - case report. Journal of Continuing Education in Veterinary Medicine and Animal Science of CRMV-SP, São Paulo, v. 19, n. 1, 2021. DOl: https://doi.org/10.36440/recmvz.v19i1.38197.
\end{abstract}

\section{Resumo}

A dermovilite exsudativa vegetante crônica (DEVC) é uma afecção que acomete os cascos de equinos, comprometendo seu bem-estar e que ainda é subdiagnosticada devido à similaridade com outras doenças. $O$ presente trabalho relata o diagnóstico clínico da DEVC em um paciente equino atendido no Ambulatório de Grandes Animais do Hospital Veterinário da Universidade Federal Rural de Pernambuco. 0 paciente de doze anos de idade, $386 \mathrm{~kg}$ e sem raça definida apresentava histórico de crescimento irregular dos cascos, com odor fétido, presença de tecido esponjoso nas ranilhas e claudicação. Foi realizado o debridamento das lesões, antissepsia dos cascos, colocação de bandagens acolchoadas e impermeabilização, além de administração de penicilina benzatina e flunixina meglumina. Apesar das lesões patognomônicas possibilitarem o diagnóstico clínico de DEVC, ainda é necessária a ampliação dos conhecimentos a seu respeito para possibilitar a sua prevenção e diagnóstico.

Palavras-chave: Pododermatite. Cancro da Ranilha. Diagnóstico Clínico. Membros Pélvicos.

\section{Abstract}

Chronic equine proliferative pododermatitis is a condition that affects the horse hooves, compromising their welfare. Despite its clinical importance, it is still underdiagnosed due to its similarity to other diseases. Therefore, the present study aimed to report the clinical diagnosis of this disease in an equine patient seen at the Ambulatory of Large Animals of the Veterinary Hospital of the UFRPE.

1 Discente, Universidade Federal Rural de Pernambuco, Departamento de Medicina Veterinária, Recife, PE, Brasil

2 Residente, Universidade Federal Rural de Pernambuco, Departamento de Medicina Veterinária, Recife, PE, Brasil

3 Docente, Universidade Federal Rural de Pernambuco, Departamento de Medicina Veterinária, Recife, PE, Brasil 
The twelve-year-old patient, $386 \mathrm{~kg}$ body weight and mixed-race, presented a history of hooves with irregular growth and malodorous odor, presence of spongy tissue in the frogs and lameness. Initial treatment consisted of debridement of the lesions, antisepsis of the hooves, the placement of padded bandages, waterproofing, and the administration of Benzathine penicillin and flunixin meglumine. Despite the pathognomonic lesions making possible the clinical diagnosis of this disease, it is still necessary to expand knowledge about it, for the improvement of its prevention and diagnosis.

Keywords: Pododermatitis. Equine Hoof Canker. Clinical Diagnosis. Hindlimbs.

\section{Introdução}

A dermovilite exsudativa vegetante crônica (DEVC) ou pododermatite hipertrófica é conhecida popularmente como cancro da ranilha e se caracteriza como uma afecção que acomete os cascos de equinos de maneira crônica (LACERDA NETO et al., 2001). A enfermidade ocorre nos tecidos queratogênicos e é caracterizada pela presença de lesões papilomatosas, exsudato purulento e desintegração ou descolamento do tecido córneo (GRECO et al., 2007). A região mais afetada é a da ranilha e seus sulcos, mas também pode afetar talões, bulbos, sola e parede do casco (AZZOLINl; BASTOS; BARROS, 2019).

A etiologia da DEVC ainda não está definida e, durante muitos anos, esteve associada a baixas condições de higiene das instalações e dos cascos (GRECO et al., 2007; LACERDA NETO et al., 2001). Atualmente, outras hipóteses são discutidas envolvendo sua relação com agentes infecciosos, como bactérias anaeróbias, vírus, espiroquetas e fungos, ou a uma resposta imunológica devido a predisposição genética (AZZOLINI; BASTOS; BARROS, 2019; BRANDT et al., 2011).

Apesar da DEVC apresentar maior prevalência em membros posteriores de cavalos de tração, atualmente já foi constatado que ela pode estar presente em diversas raças e ocorrer em um ou mais cascos, sendo relatada em todos os quatro membros (BRANDT et al., 2011; OOSTERLINCK et al., 2011). As funções de trabalho ou lazer e o bem-estar dos animais são comprometidos devido à instabilidade desenvolvida e à claudicação nos estágios finais dessa doença (APPRICH et al., 2017; BRANDT et al., 2011).

O tratamento da DEVC deve ser realizado o mais breve possível, pois a sua demora pode ocasionar o acometimento de estruturas importantes localizadas sob o tecido dérmico, tais como o tendão flexor digital profundo e a falange distal (LACERDA NETO et al., 2001). Normalmente, é realizado a partir do debridamento cirúrgico do tecido afetado ou a partir do uso de fármacos com aplicação tópica que apresentem ação antibiótica ou efeito cáustico (AZZOLINI; BASTOS; BARROS, 2019).

Oosterlinck et al. (2011) referem que a DEVC ainda é subdiagnosticada e, embora haja o conhecimento a respeito das características da doença por parte dos profissionais atuantes, o seu diagnóstico inicial raramente é correto e são adotadas medidas terapêuticas inadequadas. 0 presente trabalho relata o diagnóstico clínico de dermovilite exsudativa vegetante crônica em um paciente equino atendido no Ambulatório de Grandes Animais do Hospital Veterinário da Universidade Federal Rural de Pernambuco(UFRPE), Campus Sede, Recife, (PE).

\section{Descrição do caso}

Paciente equino, doze anos de idade, pesando $386 \mathrm{~kg}$, sem raça definida, deu entrada no Ambulatório de Grandes Animais da UFRPE, apresentando histórico de crescimento irregular dos cascos e presença de tecido esponjoso nas ranilhas. 0 proprietário relatou que havia adquirido o animal há cerca de um mês do atendimento e que ele já apresentava as alterações. Durante esse período, houve a piora do quadro, de modo que o animal passou a exibir claudicação e odor fétido nos cascos. 
Durante a avaliação física, foi observada hiporexia, magreza e elevação da frequência cardiorrespiratória (48 bpm e $18 \mathrm{mpm}$, respectivamente). Ao exame físico específico foi observado achinelamento em todos os cascos (Figuras 1A e 2A), e claudicação grau 2, de acordo com a classificação de Stashak (2006). A muralha dos cascos dos quatro membros apresentava alteração no desenvolvimento, com inúmeras fissuras e pequenas rachaduras (Figuras $1 \mathrm{~A}$ e $2 \mathrm{~A}$ ), evidenciando 0 comprometimento da estrutura e tecido infiltrativo com secreção necrótica de odor fétido nas ranilhas.

Figura 1 - Aspecto da dermovilite exsudativa vegetante crônica em equino, membros torácicos A - evidencia-se a presença de rachaduras nas muralhas dos cascos e seu achinelamento, além de alteração do estojo córneo; B - ranilha com presença de tecido de coloração amarelada e aspecto esponjoso, formato arredondado, bordos irregulares e ausência dos sulcos laterais e medial
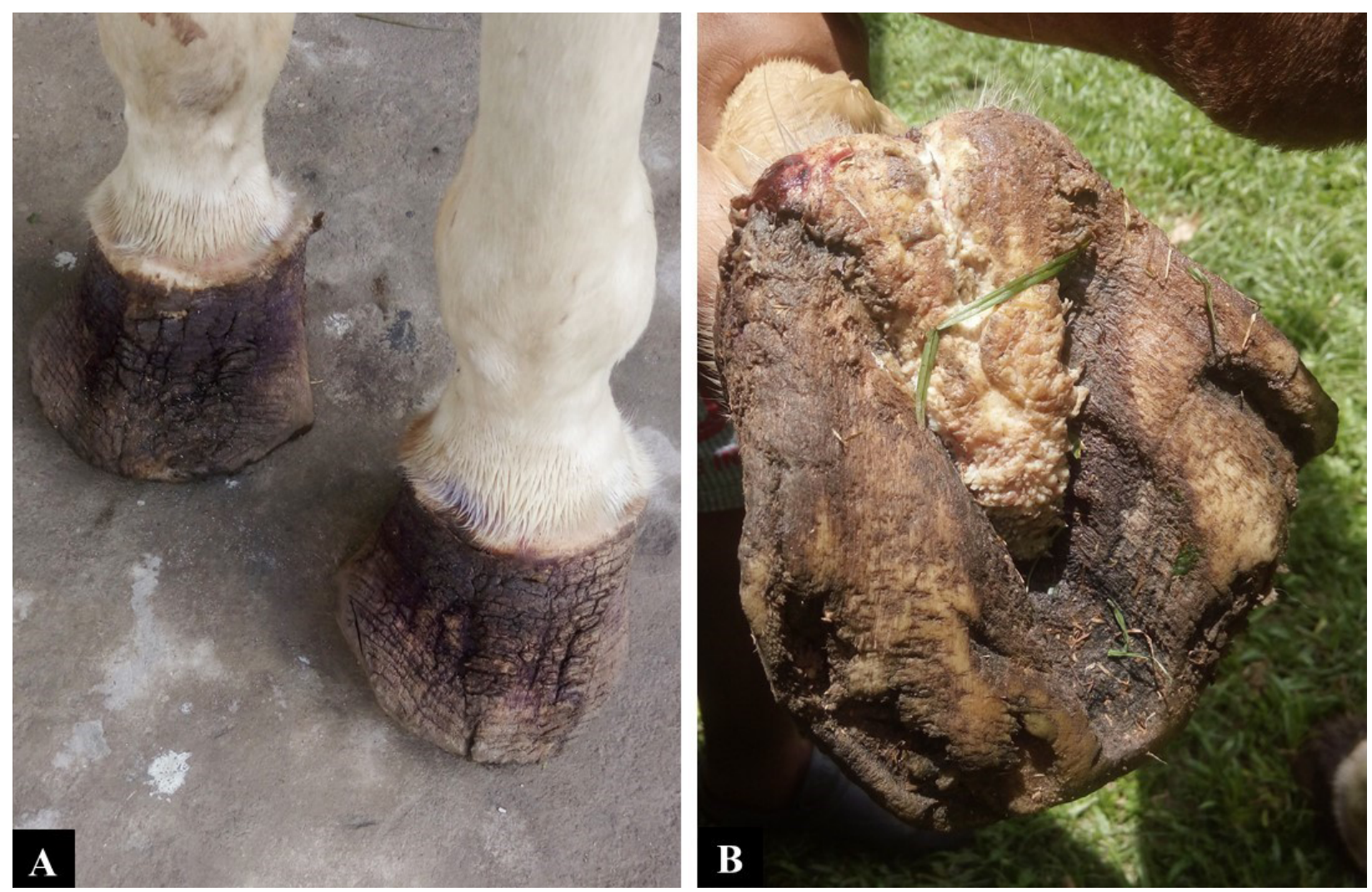

TFonte: Os autores (2019).

Após a remoção da secreção, foi observado tecido de coloração amarelada e aspecto esponjoso facilmente debridável. As ranilhas apresentavam formato arredondado com bordos irregulares e ausência dos sulcos laterais e medial (Figuras 1B e 2B) e sangravam ao serem manipuladas. Com base no histórico e nos achados clínicos observados, foi diagnosticado o quadro de dermovilite exsudativa vegetativa crônica. 
Figura 2 - Aspecto da dermovilite exsudativa vegetante crônica em equino, membros pélvicos A - evidencia-se a presença de achinelamento dos cascos e de rachaduras em suas muralhas; B - ranilha com presença de tecido de coloração amarelada e aspecto esponjoso, formato arredondado, bordos irregulares e ausência dos sulcos laterais e medial.
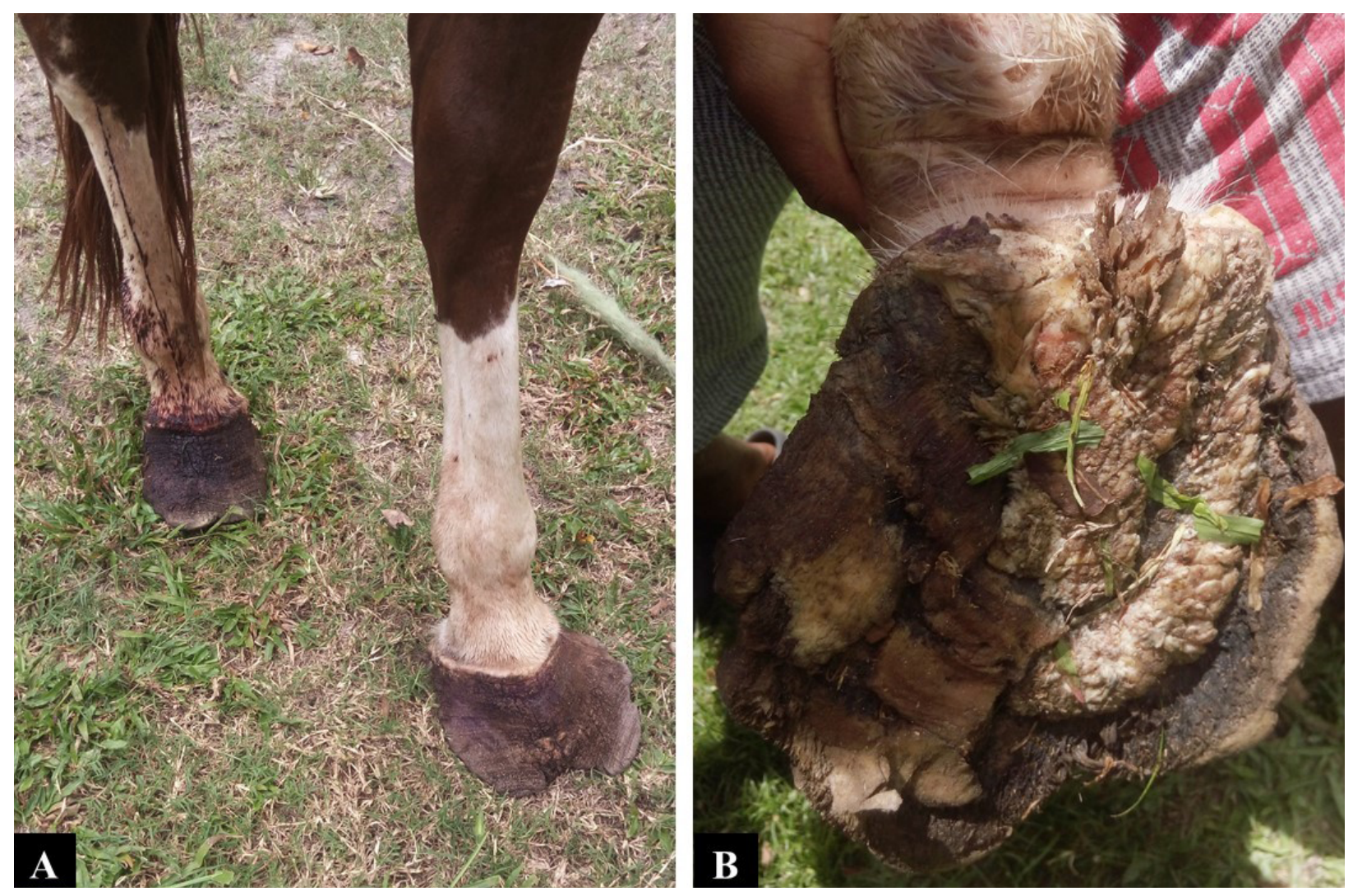

TFonte: Os autores (2019).

A terapêutica inicial consistiu no debridamento das lesões com auxílio de rineta e antissepsia dos cascos com iodopovidona degermante $10 \%$, colocação de bandagens acolchoadas com algodão ortopédico e impermeabilização com fita adesiva. Sistemicamente foi administrado penicilina benzatina (20.000 Ul/kg, via intramuscular a cada 24 horas, durante 10 dias) e flunixina meglumina $(1.1 \mathrm{mg} / \mathrm{kg}$, via intravenosa a cada 24 horas, durante 5 dias).

Como complemento às medidas terapêuticas, foi recomendado o casqueamento dos quatro cascos, limpeza diária com iodopovidona degermante 10\%, aplicação de solução à base de sulfato de cobre e substituição das bandagens até que ocorresse a completa cicatrização das lesões. Por fim, foi recomendado aumentar a espessura da cama da baia, proceder limpeza diária evitando acúmulo de fezes ou sujidades, e a substituição semanal do material. do paciente.

Devido às restrições financeiras do proprietário, não foi realizado o acompanhamento posterior

\section{Discussão}

A dermovilite exsudativa vegetante crônica era tradicionalmente considerada uma doença que acometia os membros pélvicos de cavalos de tração. Porém, a partir do início do século atual houve uma mudança nesse pensamento. Lacerda Neto et al. (2001) observaram um total de 87,5\% dos casos avaliados ocorrendo em membros torácicos. Nagamine et al. (2005) reportaram a ocorrência da DEVC em membros torácicos e pélvicos em um paciente, estando de acordo com o presente relato, visto que 
o paciente apresentou acometimento de todos os cascos.

Diferentemente desse relato, alguns pacientes com DEVC podem não apresentar alterações nos parâmetros clínicos, a exceção dos cascos (NAGAMINE et al., 2005). Todavia, aumento da frequência cardiorrespiratória e presença de claudicação são alterações comumente atribuídas à instalação de um processo doloroso e, no caso da DEVC, sugerem o comprometimento de estruturas mais profundas (THOMASSIAN, 2005).

A observação cautelosa das manifestações clínicas do paciente é um dos recursos que garante o diagnóstico preciso, tornando possível o estabelecimento de uma terapêutica favorável. No entanto, durante a fase inicial da doença, quando o caráter infiltrativo da DEVC ainda não foi atingido, o seu diagnóstico pode ser confundido com o da pododermatite exsudativa da ranilha (PER), conhecida popularmente como broca de casco (LACERDA NETO et al., 2001; OOSTERLINCK et al., 2011). Oosterlinck et al. (2011) ressaltam a importância de se promover a ampliação do conhecimento dos profissionais a respeito das duas doenças para evitar possíveis erros de diagnóstico.

A comparação da DEVC com a PER revela que na PER há predileção de ocorrência de lesões na região do sulco da ranilha, enquanto a DEVC apresenta maior extensão e tende a sangrar quando manipulada. Oosterlinck et al. (2011) consideram que os sinais patognomônicos da doença são: proliferação de tecido epitelial de massas filamentosas e odor fétido que, normalmente, se estende até a porção caudal da ranilha. Tais sinais também foram observados no presente relato.

0 tratamento da dermovilite exsudativa vegetante crônica é controverso (REDDING; O'GRADY, 2012), desafiador e pode apresentar recorrência (STASHAK, 2006), conforme Nagamine et al. (2005). 0 protocolo terapêutico adotado no presente relato com o emprego do debridamento cirúrgico da lesão, utilização de soluções tópicas e impermeabilização dos cascos por meio de bandagens são medidas que apresentam resultados satisfatórios, conforme reportam Lacerda Neto et al., 2001, Oosterlinck et al., 2011, Apprich e Licka, 2013. No entanto, não houve o acompanhamento posterior do paciente, visto que seu proprietário apresentava restrições financeiras. Por fim, foram sugeridas melhorias na cama da baia e na higiene da instalação, visto que a DEVC pode ser favorecida pela presença de umidade tanto do ambiente quanto do acúmulo de fezes, sendo necessário que o animal seja alojado em ambientes limpos e salubres (REDDING; O'GRADY, 2012).

\section{Conclusão}

Conclui-se que a DEVC apresenta lesões patognomônicas que possibilitam o seu diagnóstico clínico e a adoção da terapêutica adequada. No entanto, ainda é necessária a ampliação dos conhecimentos dessa doença pelos pesquisadores e profissionais atuantes em campo, para que os procedimentos relacionados a sua prevenção e diagnóstico possam ser aprimorados.\&

\section{Referências}

APPRICH, V. et al. Equine hoof canker: cell proliferation and morphology. Veterinary Pathology, [s.I.], v. 54, n. 4, p. 661-668, 2017. DOI: https://doi.org/10.1177/0300985817695515.

APPRICH, V.; LICKA, T. Equine hoof canker: a clinical trial of topical cisplatin chemotherapy. Veterinary Record, [s.I.], v. 172, n. 9, p. 238-240, 2013. DOI: https://doi.org/10.1136/vr.101359.

AZZOLINI, E. F. O. T.; BASTOS, S. F.; BARROS, R. M. Chronic equine proliferative pododermatitis: case report. Brazilian Journal of Veterinary Research and Animal Science, [s.l.], v. 56, n. 4, p. 1-4, 2019. DOI: https://doi.org/10.11606/issn.1678-4456.bjvras.2019.160249.

BRANDT, S. et al. Consistent detection of bovine papillomavirus in lesions, intact skin and peripheral 
blood mononuclear cells of horses affected by hoof canker. Equine Veterinary Journal, [s.l.], v. 43, n. 2, p. 202-209, 2011. DOI: https://doi.org/10.1111/j.2042-3306.2010.00147.x.

GRECO, M. et al. Un grave caso di osteomielite della seconda e terza falange con estesa perdita di sostanza in una puledra complicato da pododermatite cronica ipertrofica: follow-up a 36 mesi. Ippologia, [s.I.], v. 18, n. 1, p. 9-14, 2007.

LACERDA NETO, J. C. et al. Observações clínicas, anatomopatológicas e tratamento de seis casos de dermovilite exsudativa vegetante crônica (cancro da ranilha) de equinos. Arquivo Brasileiro de Medicina Veterinária e Zootecnia, [s.I.], v. 53, n. 3, p. 303-309, 2001. D0l: https://doi.org/10.1590/ S0102-09352001000300006.

NAGAMINE, C. M. et al. Proliferative pododermatitis (canker) with intralesional spirochetes in three horses. Journal of Veterinary Diagnostic Investigation, [s.I.], v. 17, n. 3, p. 269-271, 2005. DOI: https://doi.org/10.1177/104063870501700311.

OOSTERLINCK, M. et al. Retrospective study on 30 horses with chronic proliferative pododermatitis (canker). Equine Veterinary Education, [s.I.], v. 23, n. 9, p. 466-471, 2011. DOI: https://doi. org/10.1111/j.2042-3292.2010.00213.x.

REDDING, W. R.; O'GRADY, S. E. Nonseptic diseases associated with the hoof complex. Veterinary Clinics of North America: Equine Practice, [s.I.], v. 28, n. 2, p. 407-421, 2012. DOI: https://doi. org/10.1016/j.cveq.2012.06.006.

STASHAK, T. S. Claudicação em equinos segundo Adams. 5. ed. São Paulo: Roca, 2006. 1093 p. THOMASSIAN, A. Enfermidades dos cavalos. 4. ed. São Paulo: Livraria Varela, 2005. 574 p. 